\title{
A multifactor model of stock returns with endogenous regime switching
}

\author{
Patrick Coggi and Bogdan Manescu \\ January 2004 D iscussion paper no . 2004-01
}


Editor:

Publisher:

Electronic Publication:
Prof. Jörg Baumberger

University of St. G allen

Department of Economics

Bodanstr. 1

CH-9000 St. Gallen

Phone ++41712242241

Fax ++41712242885

Email_joerg.baumberger@unisg.ch

Forschungsgemeinschaft für $\mathrm{N}$ ationalökonomie an der U niversität St. Gallen

Dufourstrasse 48

$\mathrm{CH}-9000$ St. Gallen

Phone $\quad++41712242300$

Fax $\quad++41712242646$

www.fgn.unisg.ch/public/public.htm 


\section{A multifactor model of stock returns with endogenous regime switching}

Patrick Coggi und Bogdan Manescu

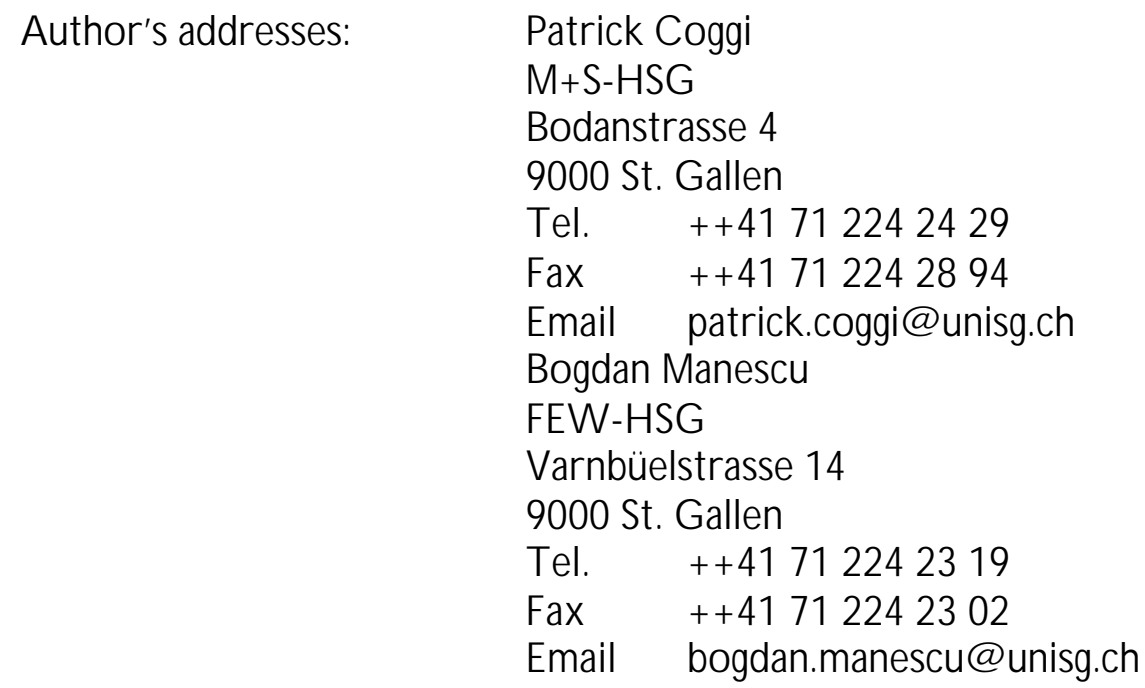

W e are especially grateful to Jörg Baumberger, Franz Jaeger, Heinz Müller and Paul Söderlind for their helpful comments and support. We also thank all participants at the 11th research seminar of the Institute for Empirical Economics and Economic Policy, University of St. Gallen. 


\begin{abstract}
:
This paper studies multifactor asset pricing in the presence of Markov regime switches. We present a state-dependent version of the Fama and French (1993) model. Performance of the unconditional Fama-French model is quite poor in some subperiods, in particular in recent years. The regime-switching model seems to overcome most of these shortcomings. We find strong evidence that two separate regimes coexist, one of which is characterized by a very high factor loading on the value risk factor. Comparison of the dynamics of the transition probabilities with major macroeconomic indicators suggest the interpretation of this state as a financial-distress regime, therefore giving support to the risk-based explanation of the size and value "anomalies". In a forthcoming paper we will present evidence for the Swiss equity market as well as applications of the model to asset allocation.
\end{abstract}

\title{
Keywords:
}

Empirical asset pricing, endogenous regime switching, state-dependent models, nonstandard maximum-likelihood estimation

\section{JEL classification:}

C52, G10, G11, G12 


\section{Introduction}

It is nowadays well recognized that the CAPM cannot explain the average returns of many investment opportunities: we need factors, sources of priced risk, beyond changes in the market portfolio in order to explain cross sectional variations in average returns. Multifactor models extend the CAPM precisely in this sense, attributing high average returns to positive correlation with additional risk factors other than movements in market risk. Multifactor models can be constructed using two completely different techniques. The first methodology (e.g. Connor and Korajczyk (1986)) extracts common factors from the sample covariance matrix of returns using factor or principal component analysis. The second technique first assigns assets to several groups based on certain characteristics so that sample mean returns differ across the groups. The difference in average returns across the groups is then used as a factor in a multifactor pricing relation. This is the approach used by Fama and French (1993) in constructing their three-factor model (FF-model, in what follows). In this paper we focus precisely on the FF-model, certainly the most popular multifactor model and nowadays playing a very prominent role in empirical financial research, dominating the performance attribution and explanation of average returns. Motivated by an attempt to explain the size and value CAPM-anomalies (observed by Banz (1981) and Rosenberg et al. (1985), respectively) the Fama-French three-factor model largely captures the average returns on U.S. portfolios formed on size and book-to-market, but also on other variables known to cause problems for the CAPM (earnings/price, cashflow/price, past sales growth and long-term past returns), see Fama and French (1996). Moreover, Fama and French (1998) claim that the international version of their model describes well the average returns on portfolios in 13 major markets.

However, recent empirical evidence questions the usefulness of these models. Most of the criticism has focussed on the distress premia identified by Fama and French (1993). Lakonishok et al. (1994) regard the distress premia for a real but irrational phenomenon, resulting from investors' overreaction leading to underpricing of distressed stock and overpricing growth stocks. On the other hand, MacKinlay (1995) views the distress premia as the product of data snooping: a variable related to average returns, but just in the sample used to identify it. A further attack to the FF-model comes from Daniel and Titman (1997), suggesting that the value premia traces for characteristics, not risk. Assume for example that investors irrationally like growth stocks and dislike value stocks: the result is a premia that is not due to risk. In a typical test, Daniel and Titman (1997) show that one cannot distinguish the risk story from the characteristics story: industries moves through periods of distress and growth, so that when we form portfolios to capture a risk factor related to relative distress, the portfolios pick up return covariation within industries 
that is always present, but that for the moment seems to be associated with growth or distress.

In this paper we focus on another potential limitation of the (unconditional) FF-model, namely its implicit assumption of constant model coefficients. There is nowadays large evidence of time-variation in betas and expected returns (as well as return volatilities) over the past two decades and a growing literature is emerging on testing conditional asset pricing models. Recent tests of conditional FF-models (He et al. (1996), Ferson and Harvey (1999)) cast serious doubts on the empirical performance of the model and clearly reject its conditional versions, generating the impression that the conditional FF-model fails miserably at dynamics of asset returns. These tests results seem surprising, as one would expect that by allowing for time-varying betas and risk premia, dynamic versions of the FF-model should perform even better. One explanation is the critique by Ghysels (1998). In fact, while the idea of time-varying betas and risk premias is theoretically very appealing, it is empirically extraordinarily challenging since there is no theoretical guidance on how betas and risk premia vary with variables that represent conditioning information. Ghysels (1998) stressed the impact of misspecification of beta risk dynamics on inference and estimation, and showed that several well-known time-varying beta models are seriously misspecificed, such that they are often outperformed by constant beta models. (One notable exception is the nonparametric approach by Wang (2002).)

We tackle the problem of modelling the dynamics in model parameters from a completely different perspective. Rather than being time-varying in the usual sense, we allow the parameters to switch in regime. Several fundamental changes in the economic environment come in the form of discontinuous changes. Shifts in economic policy or major exogenous economic events influencing financial time series, can be viewed as episodes of identifiable duration in which the behaviour of key economic series might be expected to differ significantly form that seen outside these episodes. In an attempt to capture these facts we develop a version of FF-model where the parameters are subject to markovian regime switches and test for its validity. The methodology is inspired by Hamilton (1990). With an eye on practical applications, we keep the model in its simplest form, namely with only two endogenous regimes. Of course, our model is a very special conditional one, since the information set on which we condition consists only of two states. However, this approach has several advantages. Only the probability law governing the shifts - a simple Markov chain - needs to be specified, thus minimising the risk of misspecifications. Our task is then to determine when the shifts occur and to estimate the parameters in the different regimes. Moreover, our models nests the FF-model and thus allows direct comparison of the results.

The paper is structured as follows. We start by reviewing the traditional FF- 
model. We then extend the estimation period to December 2002 and present estimation and testing results. In the third section we present the regime switching methodology and develop our multifactor model. We assume that the FF specification holds true in both regimes, but allow factor loadings to vary across states. This permits to endogenously identify the different regimes and to compute the Markov probabilities. We present these results in detail in section 3.2. In section 4, we turn to testing the FF- model in a regime switching context. We find that the model performs fairly well. Later in section 4.3 we look at the alternation of regimes over the last 70 years. A striking feature of the our model is how well it captures the main episodes of aggregate financial distress. We conclude by formulating some recommendations about the use of the different models in normal and "distressed" times.

\section{Fama \& French 3-factor models}

\subsection{Methodology}

Similarly to Fama and French (1993) we test the FF-model using the timeseries regression approach of Black et al. (1972), since it allows to capture the variation in the different factor loadings and to identify the market's regimes. Moreover, the time-series regression slopes have the clear interpretation as risk-factor sensitivities. In a time-series regression a correctly specified model produces intercepts that are not significantly different from zero. Thus, the estimated intercept provide a simple formal test for comparing the performance of different asset pricing models.

The model attempts to explain the returns for 25 stock portfolios formed on the basis of size and book-to-market equity. The explanatory variables are the returns on a market portfolio and mimicking portfolios for size (ME, i.e. market capitalization) and book-to-market equity (BE/ME, i.e. book value relative to stock price). The market factor is proxied by the excess market return, RM-RF, where RM is the return on the value-weighted portfolio of the stocks in the six portfolios above. RF is the one-month Treasury bill rate. The model is then used to explain the excess returns on the 25 portfolios formed from the intersections of five size and five BE/ME quintiles in the same way as the six portfolios above.

Size and book-to-market are related to profitability. It is a well known fact (at least since Banz (1981)) that controlling for book-to-market equity, small firms tend to have lower earnings on assets than big firms. On the other hand, firms with high $\mathrm{BE} / \mathrm{ME}$ tend to have low earnings on assets (e.g. Rosenberg et al. (1985)). The interpretation of these facts by Fama and French (1993) 
is that size is associated with a common risk factor explaining the negative relationship between size and average returns, and similarly that a common risk factor in returns is the source of the positive relation between BE/ME and average returns. To mimic the risk factor related to size, Fama and French form each month the SMB-portfolio as the difference in the simple average of monthly returns between small- and big-stock portfolios with approximatively the same BE/ME. More specifically, SMB is the difference between returns on the three small-stock portfolios $(\mathrm{S} / \mathrm{L}, \mathrm{S} / \mathrm{M}, \mathrm{S} / \mathrm{H})$ and the three big-stock portfolios $(\mathrm{B} / \mathrm{L}, \mathrm{B} / \mathrm{M}, \mathrm{B} / \mathrm{H})$. Similarly, to proxy the risk factor related to $\mathrm{BE} / \mathrm{ME}$, the HML factor is the difference, each month, between the average of the returns on the two high- $\mathrm{BE} / \mathrm{ME}$ portfolios $\mathrm{S} / \mathrm{H}$ and $\mathrm{B} / \mathrm{H}$, and the average of the returns on the two low-BE/ME portfolios $\mathrm{S} / \mathrm{L}$ and $\mathrm{B} / \mathrm{L}$. This is the "traditional" interpretation of SMB and HML, i.e. as proxy for sensitivity to common (systematic, undiversifiable) risk factors. In this sense, e.g. the HML factor is often interpreted as a measure of aggregate financial distress (Fama and French (1995)). There is a continuing argument in the literature over the status of the size and BE/ME factors. Alternatively, one can in fact view the model as an arbitrage pricing theory in which the returns of the three-factor mimicking portfolios aim at perfectly replicating the returns of the 25 portfolios.

\subsection{The US case: summary of results}

We start by running the 25 times-series regressions for US CRSP and Compustat data for different sub-sample periods. The data are publicly available through Kenneth French's internet page.We extend the two estimation periods of Fama and French (1993) and (1996) up to December 2002 (regression 1 ), and then split this last time period in 4 subperiods (regressions 2 to 5). We start by reviewing the results of Fama and French (1993) and Fama and French (1996) and compare them with our findings.

\subsubsection{Fama and French (1993): July 1963-December 1991}

Fama and French (1993) find that the three factors capture strong common variation in the stock return data. All $\beta$ 's are significant (the lowest $t$-value is 38.61), and so are the SMB (all $t$-statistics but one above 4) and the HML slopes (most $t$-values around 5, slope on the second BE/ME quintiles is not significant). As expected, the slopes on SMB decrease monotonically in each book-to-market quintile, from smaller- to bigger-size quintiles. Similarly, the slopes on HML increase from negative to positive value within each BE/ME quintile. Both SMB and HML seem to capture variation in stock returns that are missed by the market factor. All regressions $R^{2}$ are very high, with 20 
coefficients being higher than 0.9. The lowest $R^{2}$ is found for the regression in the largest-size and highest-BE/ME quintile, and amounts to 0.83. For simple CAPM regressions using the same dataset and estimation period only two $R^{2}$ are bigger than 0.9. These high $R^{2}$ show that stock returns have common variation related to all the three factors. Fama and French (1993) interpret this as evidence that stock market returns, SMB, HML and RM-RF proxy for risk factors. With respect to the CAPM, the $\beta$ s collapse towards one, with low $\beta \mathrm{s}$ (smallest-size, lowest BE/ME) moving towards 1 and high $\beta$ s (big size, big BE/ME) moving down. As Fama and French (1993) point out, this result is due to SMB and HML correlating with the market.

\subsubsection{Fama and French (1996): July 1963-December 1993}

For the sub-sample July 1963-December 1993 Fama and French (1996) find similar results, albeit the model now produces large negative pricing errors for the portfolio of largest size and lowest BE/ME. All other intercepts are undistinguishable from zero, their average is 0.093 percent (about nine basis points). Recall that if the model holds, the true intercepts equal zero. When examining whether the risk factors explain the cross-section of mean returns, we can focus on the intercept estimates of the multivariate regression system. This can be performed by examining $t$-statistics or using the adjusted Wald statistic proposed by Gibbons et al. (1989). The average $R^{2}$ is 0.93 for this sample period.

\subsubsection{Regression 1: form July 1963 to December 2002}

The average price error is now about 47 basis points, i.e. about five time higher than in Fama and French (1996), and 24 pricing errors are significantly different from zero. The average $R^{2}$ is 0.9 .

\subsubsection{Regression 2: 1963-1972}

For this sub-sample, the average pricing error is at 0.35 and the average $R^{2}$ is 0.92. Interestingly, the HML coefficient is not significant for all low BE/ME portfolios, i.e. for about one third of the portfolios.

\subsubsection{Regression 3: 1973-1982}

The average $R^{2}$ is 0.93 , whereby the average pricing error increases to 69 basis points. The $R^{2}$ for the largest size-largest BE/ME is now particularly low at 0.77 . 
The model produces large significant pricing errors for all portfolios. Interestingly, the largest size-largest BE/ME portfolio, which produces large pricing errors in Fama and French $(1993,1996)$, is now the one with the smallest pricing error. Again, the HML coefficient is not significant for most of the BE/ME portfolios.

\subsubsection{Regression 4: 1983-1992}

The average pricing error for this subsamble is 0.58 and the average $R^{2}$ is 0.94. The pricing errors are significantly different from zero. For 24 portfolios the HML coefficients are significant and the P-values are higher than in the preceding decade for every coefficient. Interestingly, the $\beta$ s for low size-low $\mathrm{BE} / \mathrm{ME}$ are now sensibly lower, while they are higher for high size-low BE/ME portfolios.

\subsubsection{Regression 5: 1993-2002}

FF-model produces an average pricing error of 35 basis points. All pricing errors but nine are significantly different from zero. The average $R^{2}$ is 0.87 with the lowest being $70 \%$ for the big companies with high BE/ME-ratio. All coefficients are significant. All HML coefficient are at least 4 standard deviations away from zero.

\subsection{Implications}

Giving rational pricing, the factors must contribute substantially to the risk of well-diversified portfolios, in order to justify their use in an asset pricing model. All $R^{2}$ are in a reasonable range for all decades and across all 25 portfolios. We find that the adjusted $R^{2}$ declines when the two other factors are used without the market factor. However, each factor contributes in explaining the portfolio returns. For some portfolios, adding HML increases $R^{2}$ more than adding SMB, but there is no clear ranking of the factors in their explanatory power. As expected, the estimated SMB exposures increase monotonically with size ranking, and analogously for the HML exposure, for all sub-sample periods.

The FF-model is rejected in each sub-sample period. This is to be expected. The model does capture most of the variation in the average returns. However, when we extend the regression period, the intercepts become larger and significantly different from zero. Interestingly, there seem to be times when the FF-model does a quite good job. On the contrary, and in particular in more recent subperiods such as the seventies and the nineties, when average pricing 
errors are huge, about $0.5 \%$ monthly and the adjusted $R^{2}$ drops to $70 \%$. There seem also to be times, in particular for some portfolios in the median range of the size and $\mathrm{BE} / \mathrm{ME}$ distribution, in which the market factor plays a central role in explaining stock returns, precisely in periods when the HML factor loading is smaller and/or lacks significance. In other subperiods, the HML is strongly significant whereby SMB and $\beta$ seem to have a limited explaining power. The attempt to identify and characterize the market conditions under which a particular factor better explains differences in stock returns, is one of the motivations for our regime switching methodology.

\section{A 3-factor model with regime switching}

\subsection{Methodology}

In this section we extend the estimation technique inspired by Hamilton (1990) for the case of a dynamic multifactor model. The dynamics stems from an unobservable Markov chain with two regimes or states. In each period $t=$ $1, \ldots, T$. We can be in one of the two regimes $s_{t}=1,2$ and the observable excess return is described by the following multifactor relationship.

$$
\begin{aligned}
y_{t}^{i} & \triangleq R_{t}-R F_{t}=\alpha_{i}+\beta_{i} \cdot\left[R M_{t}-R F_{t}\right]+\gamma_{i} \cdot S M B_{t}+\delta_{i} \cdot H M L_{t}+\varepsilon_{t} \\
i & =1,2 \text { depending on the regime }
\end{aligned}
$$

Under the assumption of normal distributed outcomes of the dependent variable

$$
Y_{t}^{i} \sim N\left(\mathbf{x}_{t} \beta_{i}, \sigma^{2}\right)
$$

we can write for the density of $y_{t}$, conditional on the random variable $S_{t}$ taking the values $s_{t}=i$,

$$
\begin{gathered}
f\left(y_{t} \mid s_{t}=i ; \beta_{1}, \beta_{2}, \sigma^{2}, \mathbf{x}_{t}\right)=\frac{1}{\sqrt{2 \pi} \sigma_{i}} \cdot e^{-\frac{\left(y_{t}-\mathbf{x}_{t} \beta_{i}\right)}{2 \sigma^{2}}} \\
\beta_{1}=\left(\alpha_{1} \beta_{1} \gamma_{1} \delta_{1}\right)^{\prime}, \beta_{2}=\left(\alpha_{2} \beta_{2} \gamma_{2} \delta_{2}\right)^{\prime}
\end{gathered}
$$

The probability of being in a particular state $s_{t}=i, i=1,2$ depends on the past only through the last regime $s_{t-1}$.

$$
P\left(s_{t}=j \mid s_{t-1}=i, s_{t-2}=k, \ldots\right)=P\left(s_{t}=j \mid s_{t-1}=i\right)=p_{i j}
$$

The transition probability $p_{i j}$ is the probability that state $i$ is followed by state $j$. In a homogenous Markov chain $\left\{S_{t}\right\}_{t=0,1, \ldots}$ this conditional probability is 
time-invariant. Using these transition probabilities one can define a stochastic transition matrix

$$
\mathbf{P}=\left(\begin{array}{ll}
p_{11} & p_{21} \\
p_{12} & p_{22}
\end{array}\right)=\left(\begin{array}{cc}
p_{11} & 1-p_{22} \\
1-p_{11} & p_{22}
\end{array}\right)
$$

with

i) $p_{i j} \geq 0, \forall i, j=1,2$

ii) $\sum_{j=1}^{2} p_{i j}=1, \forall j=1,2$

It follows

$$
\mathbf{P}^{\prime} 1=1
$$

If the two-state Markov chain is irreducible and the second eigenvalue of the matrix $\mathbf{P}$ lies in the unit circle, the Markov chain is called ergodic. The vector of ergodic probabilities $\pi$ associated with the unit eigenvalue is the vector of unconditional probabilities, which are also the long-run forecast for an ergodic Markov chain.

$$
\pi=\left(\begin{array}{l}
\pi_{1} \\
\pi_{2}
\end{array}\right)=\left(\begin{array}{c}
P(s=1) \\
P(s=2)
\end{array}\right), \text { regardless of the date }
$$

Thus the eigenvector $\pi$ associated with the unit eigenvalue for a two-state Markov chain is:

$$
\pi=\left(\begin{array}{c}
\frac{1-p_{22}}{2-p_{11}-p_{22}} \\
\frac{1-p_{11}}{2-p_{11}-p_{22}}
\end{array}\right), \pi_{1}+\pi_{2}=1
$$

For estimation purposes one has to find the unconditional density of $Y_{t}$ depending on the parameters $\theta=\left(\beta_{1}, \beta_{2}, \sigma^{2}, \mathbf{P}\right)$

$$
\begin{aligned}
f\left(y_{t} ; \theta, \mathbf{x}_{t}\right) & =\sum_{i=1}^{2} f\left(y_{t}, s_{t}=i ; \theta, \mathbf{x}_{t}\right) \\
& =\sum_{i=1}^{2}\left(f\left(y_{t} \mid s_{t}=i ; \theta, \mathbf{x}_{t}\right) \cdot \sum_{j=1}^{2}\left[P\left(s_{t-1}=j, s_{t}=i\right)\right]\right) \\
f\left(y_{t} ; \theta, \mathbf{x}_{t}\right) & =\sum_{i=1}^{2}\left(\frac{1}{\sqrt{2 \pi} \sigma_{i}} e^{-\frac{\left(y_{t}-\mathbf{x}_{t} \beta_{i}\right)}{2 \sigma_{i}^{2}}} \sum_{j=1}^{2} p_{j i}\right)
\end{aligned}
$$

As the transition matrix is assumed to be time-invariant we can calculate the log-likelihood function from the observed data conditional on the ergodic probabilities that the world is in one of the two possible states at time $t=0$. 


$$
\begin{aligned}
\mathcal{L}(\theta \mid \mathbf{Y}, \mathbf{X}) & =\sum_{t=1}^{T} \log f\left(\theta ; y_{t}, \mathbf{x}_{t}\right) \\
& =\sum_{t=1}^{T} \sum_{i=1}^{2} \sum_{j=1}^{2}\left(\frac{\partial \log f\left(y_{t} \mid s_{t}=i ; \theta, \mathbf{x}_{t}\right)}{\partial \theta} \cdot P\left(s_{t-1}=j, s_{t}=i\right)\right)
\end{aligned}
$$

The maximization of this likelihood function over $\theta$ subject to the constraints $p_{i j} \geq 0, i=1,2$ and $\sum_{j=1}^{2} p_{i j}=1$ leads to the maximum-likelihood estimators for the parameters in the multifactor model with two-regimes.

The estimated probabilities of being in a specific state based on observations up to date $t$ follow easily

$$
P\left(s_{t}=i ; \hat{\theta}, \mathbf{x}_{t}\right)=\frac{\sum_{j=1}^{2} f\left(y_{t}, s_{t-1}=j, s_{t}=i ; \widehat{\theta}, \mathbf{x}_{t}\right)}{f\left(y_{t} ; \hat{\theta}, \mathbf{x}_{t}\right)}, t=1, \ldots, T
$$

using the ergodic probabilities as starting values for the Markov chain.

The maximization of the log-likelihood function can be carried out via numerical optimization or via the EM-algorithm, as Hamilton (1990) proposed. van Norden and Vigfusson (1996) have shown, that these algorithms yield very similar results.

We now present an implementation of the EM-algorithm for our model. The maximum-likelihood estimator solves the following equations

$$
\begin{aligned}
& \frac{\partial \log f\left(y_{t}, s_{t}=i ; \theta, \mathbf{x}_{t}\right)}{\partial \beta_{i}}=\left\{\begin{array}{c}
\frac{\mathbf{x}_{t}^{\prime}\left(y_{t}-\mathbf{x}_{t} \beta_{i}\right)}{\sigma^{2}}, s_{t}=i \\
0, \text { otherwise }
\end{array}\right. \\
& \frac{\partial \log f\left(y_{t}, s_{t}=i ; \theta, \mathbf{x}_{t}\right)}{\partial \sigma^{2}}=\frac{\sigma^{2}}{2}-\frac{\left(y_{t}-\mathbf{x}_{t} \beta_{i}\right)^{2}}{2}
\end{aligned}
$$

If the probabilities $P\left(s_{t}=i \mid \theta, \mathbf{x}_{T}\right)$ are known, we can estimate $\beta$ and $\sigma^{2}$ using the following equations:

$$
\begin{gathered}
\sum_{t=1}^{T} \mathbf{x}_{t}^{\prime}\left(y_{t}-\mathbf{x}_{t} \widehat{\beta_{i}}\right) \cdot P\left(s_{t}=i \mid \theta, \mathbf{x}_{t}\right)=0, i=1,2 \\
\widehat{\sigma^{2}}=\frac{1}{T} \sum_{t=1}^{T} \sum_{i=1}^{2}\left(y_{t}-\mathbf{x}_{\mathbf{t}} \widehat{\beta_{i}}\right)^{2} \cdot P\left(s_{t}=i \mid \theta, \mathbf{x}_{\mathbf{t}}\right)
\end{gathered}
$$

Each observation is weighted with the probability of being in regime 1 or regime 2, i.e. the maximum-likelihood estimates are the estimates of a weighted 
least squares estimation with weights $\sqrt{P\left(s_{t}=i \mid \theta, \mathbf{x}_{t}\right)}$. We only need to estimate the unconditional probabilities to carry out the regression. The estimators for the unconditional probabilities $P\left(s_{t}=i \mid \theta, \mathbf{x}_{t}\right)$ can be obtained via equation 9 .

The EM algorithm is a robust, iterative method for finding a local MLoptimum to the above optimization problem. Beginning with an initial guess $\widehat{\theta}^{0}$ we calculate using formula 9 the probability $P\left(s_{t}=i \mid \widehat{\theta}^{0}, \mathbf{x}\right)$ and maximumlikelihood parameter estimates for ${\widehat{\beta_{1}}}^{1},{\widehat{\beta_{2}}}^{1}{\widehat{\sigma^{2}}}^{1}$ using equations 8 and 12 .

The estimator for $\widehat{\mathbf{P}}^{1}$ is obtained using equations

$$
{\widehat{p_{i j}}}^{1}=\frac{\sum_{t=2}^{T} P\left(s_{t}=j, s_{t-1}=i \mid{\widehat{\beta_{1}}}^{1},{\widehat{\beta_{2}}}^{1},{\widehat{\sigma^{2}}}^{1}, \widehat{\mathbf{P}}^{0}, \mathbf{x}_{t}\right)}{\sum_{t=2}^{T} P\left(s_{t-1}=i \mid \widehat{\beta}_{1}^{1},{\widehat{\beta_{2}}}^{1},{\widehat{\sigma^{2}}}^{1}, \widehat{\mathbf{P}}^{0}, \mathbf{x}_{t}\right)}, i, j=1,2
$$

This new estimate is used as input in the next iteration. The algorithm stops when the changes in the parameters are below a predefined accuracy.

Having estimated the transition matrix $\widehat{\mathbf{P}}$, the transition probabilities conditional on the observed vector $\mathbf{x}_{t}$ and $\hat{\theta}$ we can form a forecast for being in state $s_{t+1}=i$.

$$
\begin{aligned}
& \widehat{P_{t}}=\left(\begin{array}{l}
P\left(s_{t}=1, s_{t-1}=1 \mid \widehat{\theta}, \mathbf{x}_{t}\right) P\left(s_{t}=2, s_{t-1}=1 \mid \widehat{\theta}, \mathbf{x}_{t}\right) \\
P\left(s_{t}=1, s_{t-1}=2 \mid \widehat{\theta}, \mathbf{x}_{t}\right) P\left(s_{t}=2, s_{t-1}=2 \mid \widehat{\theta}, \mathbf{x}_{t}\right)
\end{array}\right) \\
& \widehat{\mathbf{P}}=\left(\begin{array}{l}
\widehat{p_{11}} \widehat{p_{21}} \\
p_{12} \widehat{p_{22}}
\end{array}\right)
\end{aligned}
$$

A useful representation of a Markov chain is the following

$$
\xi_{t}=\left\{\begin{array}{l}
(1,0, \ldots, 0)^{\prime} \text { when } s_{t}=1 \\
(1,0, \ldots, 0)^{\prime} \text { when } s_{t}=2
\end{array}\right.
$$

and we can write for the one-period ahead forecast of the probabilities

$$
\begin{gathered}
E\left(\xi_{t+1} \mid s_{t}=i\right)=\left[\begin{array}{l}
p_{i 1} \\
p_{i 2}
\end{array}\right] \\
\widehat{E}\left(\xi_{t+1} \mid \xi_{t}\right)=\widehat{\mathbf{P}} \xi_{t}
\end{gathered}
$$

The forecasted probabilities of being in state 1 or state 2 follow easily. 


\subsection{Data description and estimation results}

As above, we use the same the dataset as Fama and French (1993), extended and provided by Kenneth French. The sample period starts on 1931/7 and ends 2002/12. Portfolio returns are calculated monthly from 25 portfolios, formed on quintiles of size and book-to-market equity. Each year NYSE quintile breakpoints for size, measured at the end of June, are used to allocate NYSE, Amex and NASDAQ stocks to five size quintiles. Using the same procedure, NYSE breakpoints for book equity-to-market equity are used to classify all the stocks into the right $\mathrm{BE} / \mathrm{ME}$ quintile. Book equity (BE) is the Compustat book value of stockholders' equity, plus balance sheet deferred taxes and investment tax credits minus the book value of preferred stock. Market equity (ME) is price per share times shares outstanding. The risk-free rate is the rate of the one-month Treasury bill observed at the beginning of each month. As described above all NYSE stocks are ranked on size (market capitalization) and then split into two groups: small (S, size below the NYSE median) and big (B, above the median). NYSE, Amex and NASDAQ stock on CRSP are also sorted into three BE/ME groups (L, bottom 30\%, M, middle 40\%, and $\mathrm{H}$, top 30\%), excluding negative-BE stocks. From the intersections of the two size groups and the three book-to-market equity groups, six portfolios (S/L, S/M, $\mathrm{S} / \mathrm{H}, \mathrm{B} / \mathrm{L}, \mathrm{B} / \mathrm{M}, \mathrm{B} / \mathrm{H}$ ) are formed. As explanatory variables we use the valueweighted monthly percent return on all the stock in excess of the risk-free rate and two mimicking portfolio returns, SMB and HML. The SMB-factor (Small Minus Big) is the average return on the three small portfolios minus the average return on the three big portfolios. The HML-factor (High Minus Low) is the average return on the two value portfolios minus the average return on the two growth portfolios.

In table 1 we report summary statistics for all 25 portfolios and in table 2 the mean and standard deviations of the explanatory variables. The average monthly returns for the portfolios should exhibit cross-sectional variation in expected returns. The mean return on the portfolios varies from $0.858 \%$ to $1.788 \%$ per month. Standard deviations vary from $5.457 \%$ to $12.55 \%$. The average value of the market premia per unit of $\beta, R M-R F$, is $0.647 \%$ per month or $7.764 \%$ per year. The average SMB return, the average premia for the size-related factor, is $2.52 \%$ per year and the HML return, the average premia for the book-to-market related factor, is $3.276 \%$ per year. 


\begin{tabular}{crrrrr} 
& \multicolumn{5}{c}{ Mean } \\
& Low & 2 & 3 & 4 & High \\
\hline Small & 0,858 & 1,221 & 1,473 & 1,659 & 1,788 \\
2 & 0,958 & 1,285 & 1,421 & 1,488 & 1,565 \\
3 & 1,049 & 1,212 & 1,270 & 1,376 & 1,497 \\
4 & 0,990 & 1,066 & 1,249 & 1,312 & 1,433 \\
Big & 0,913 & 0,890 & 1,016 & 1,107 & 1,338
\end{tabular}

Table 1

\begin{tabular}{crrrrr} 
& \multicolumn{5}{c}{ Standard deviations } \\
& Low & 2 & 3 & 4 & High \\
\hline Small & 12,550 & 10,693 & 9,171 & 8,806 & 9,762 \\
2 & 8,140 & 7,877 & 7,539 & 7,593 & 8,746 \\
3 & 7,736 & 6,610 & 6,815 & 6,839 & 8,582 \\
4 & 6,229 & 6,332 & 6,413 & 7,127 & 9,139 \\
Big & 5,457 & 5,212 & 5,795 & 6,898 & 8,561
\end{tabular}

Summary statistics for the dependent returns in percent. Sample period July 1931 to December 2002, 918 observations.

\begin{tabular}{cccccc}
\multicolumn{3}{c}{ Mean } & \multicolumn{3}{c}{ Standard deviations } \\
RM-RF & SMB & HML & RM-RF & SMB & HML \\
\hline 0,647 & 0,273 & 0,437 & 5,431 & 3,403 & 3,651
\end{tabular}

Table 2

Summary statistics for the explanatory returns in percent. Sample period July 1931 to December 2002, 918 observations.

\section{Results and Interpretation}

\subsection{Time-series regressions}

As reported in the last section, the pricing performance of the unconditional FF-model seems to depend quite strongly on the sample period. Pricing accuracy is particularly good for 1963/7-1991/12 as in Fama and French (1993) and resp. 1963/7-1993/12 in Fama and French (1996).However, if the 25 regression are carried out for 1963-2003, the model's coefficients seem quite instable and the adjusted $R^{2}$ decreases massively. As expected, we find strong 


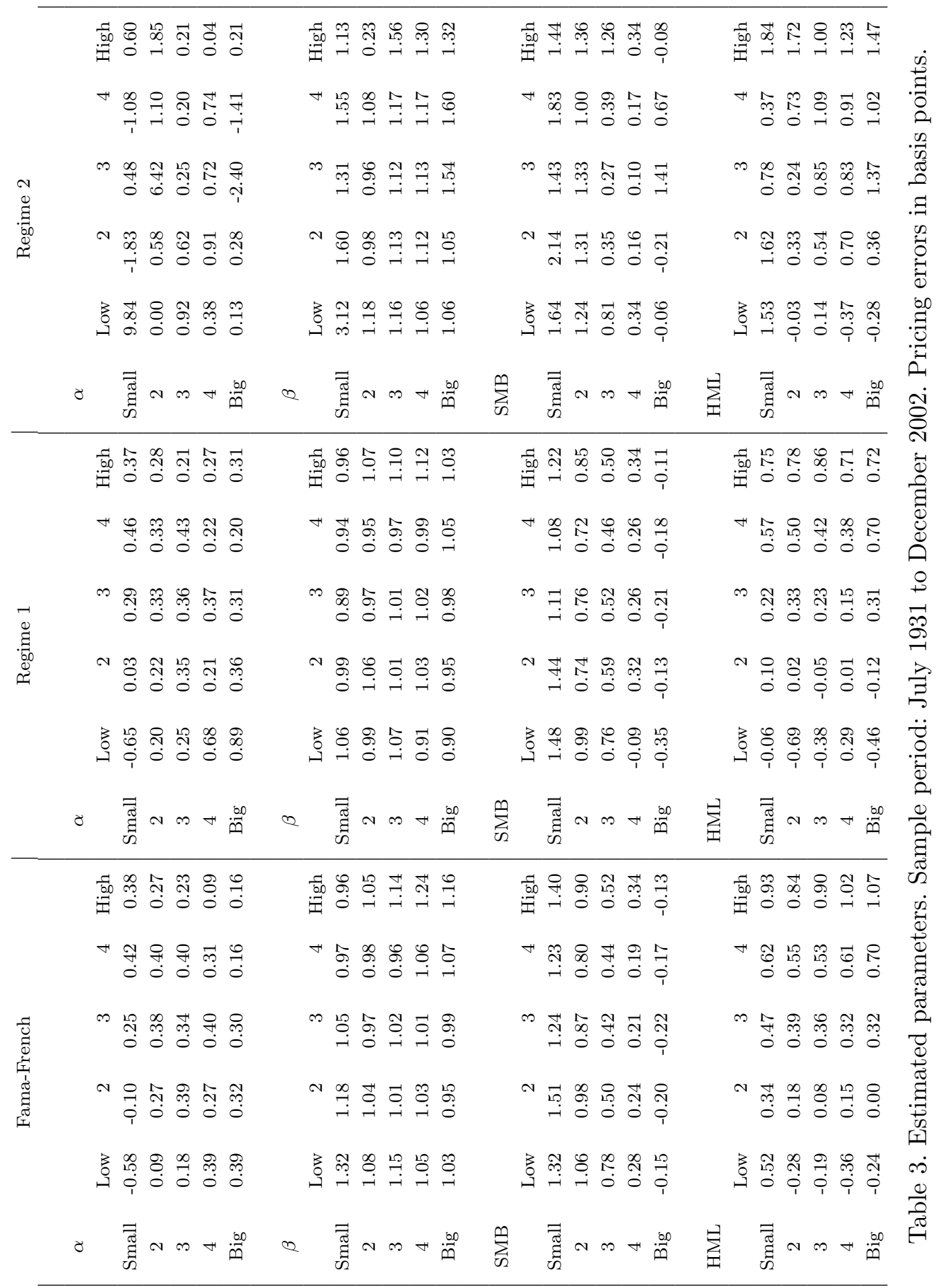




\begin{tabular}{|c|c|c|c|c|c|c|}
\hline \multirow{6}{*}{ 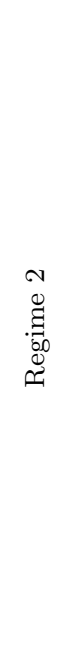 } & 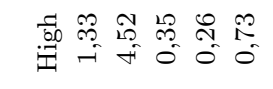 & 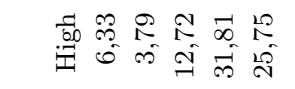 & & 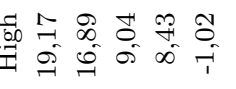 & & 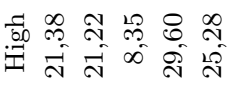 \\
\hline & 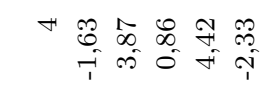 & 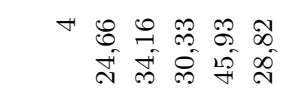 & & 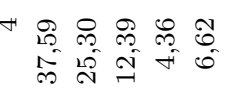 & & 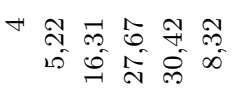 \\
\hline & 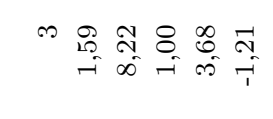 & 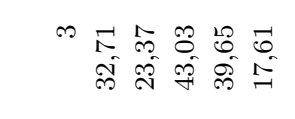 & & 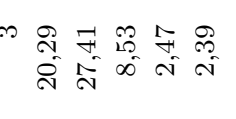 & & 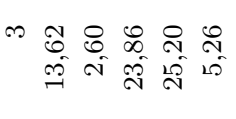 \\
\hline & 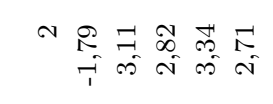 & 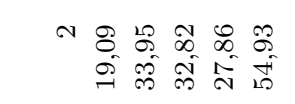 & & 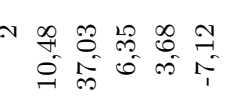 & & 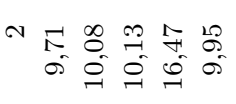 \\
\hline & 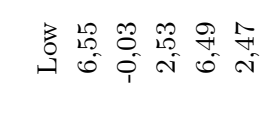 & 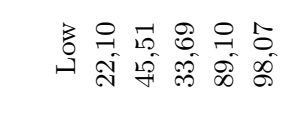 & & 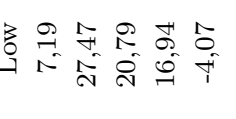 & & 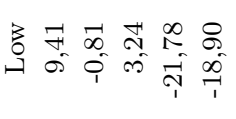 \\
\hline & 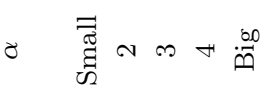 & 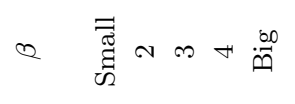 & $\sum_{i=1}^{\infty}$ & 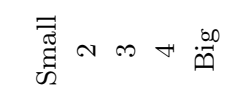 & 离 & 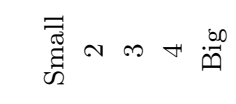 \\
\hline \multirow{6}{*}{ 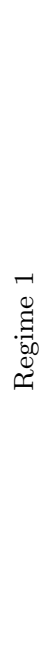 } & 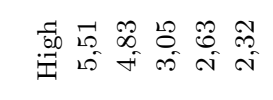 & 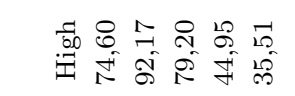 & & 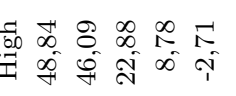 & & 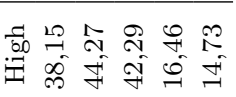 \\
\hline & 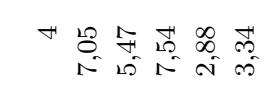 & 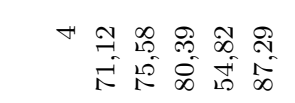 & & 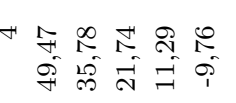 & & 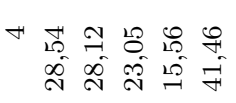 \\
\hline & 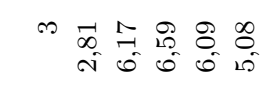 & 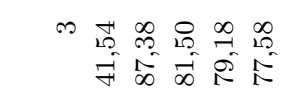 & & 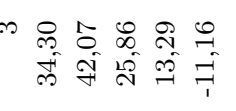 & & 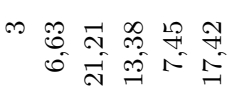 \\
\hline & 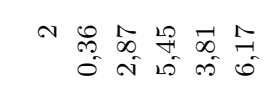 & 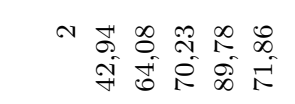 & & 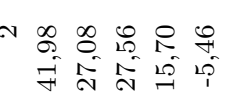 & & 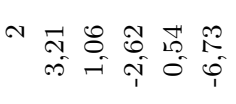 \\
\hline & 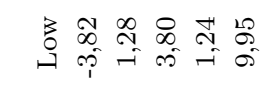 & 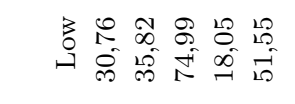 & & 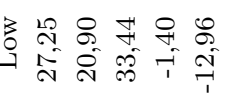 & & 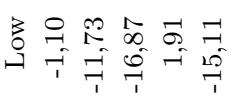 \\
\hline & 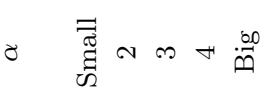 & $@ \quad \overline{\bar{G}}$ & $\sum_{n=1}^{\infty}$ & 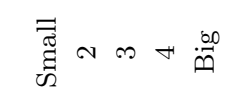 & 离 & 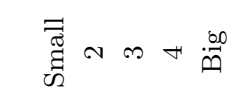 \\
\hline \multirow{6}{*}{ 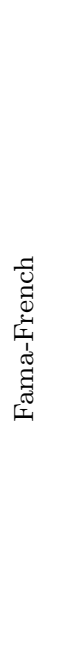 } & 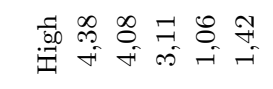 & 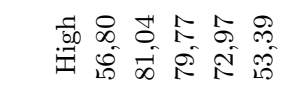 & & 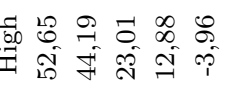 & & 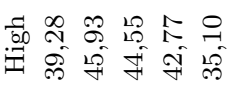 \\
\hline & 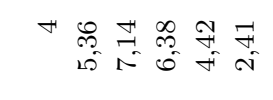 & 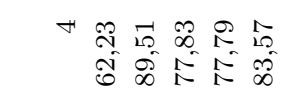 & & 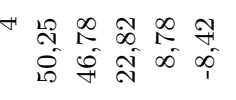 & & 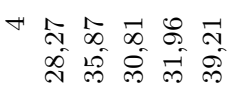 \\
\hline & 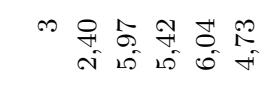 & 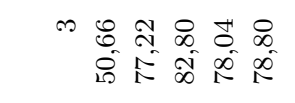 & & 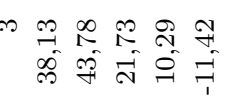 & & 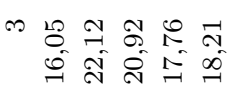 \\
\hline & 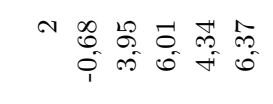 & 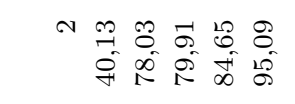 & & 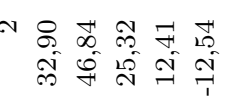 & & 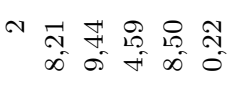 \\
\hline & 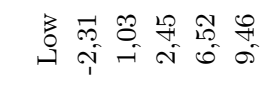 & 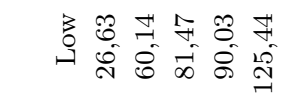 & & 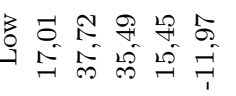 & & 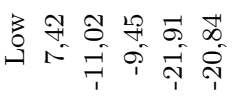 \\
\hline & 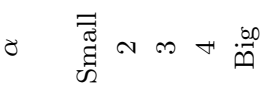 & 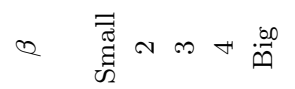 & $\sum_{i=1}^{n}$ & 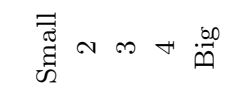 & 童 & 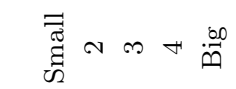 \\
\hline
\end{tabular}




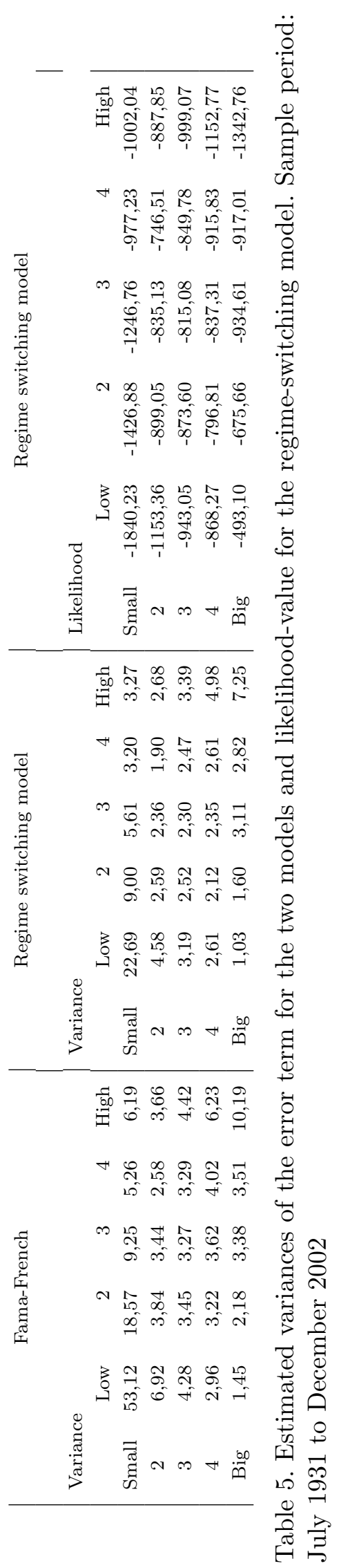


evidence for time-varying, regime-dependent risk compensations. Moreover, most of the major negative shocks on the equity market over the last seventy years correspond to times identified by our model as high-distress-probability periods, i.e. times where the distressed (a regime characterised in particular by a very high risk premia on the $\mathrm{BE} / \mathrm{ME}$ factor) is highly probable. The distressinterpretation of this regime (also suggested by Fama and French (1996)) is reinforced by the fact that distressed companies, those with a high book-tomarket ratio or a small size, are more often than other companies in a state where our model predicts abnormally high risk premia.

Tables 3, 4 and 5 present these results in detail. The estimated factor sensitivities, their $t$-statistics and the regression variances for the 25 portfolios, sorted in size- and BE/ME-quintiles, are reported for both the regime switching model (RS) and our benchmark FF model (1931-2002). The parameter values for the two regimes differ and these differences are all statistically significant. The regression variances of the RS model (Table 5) are for all the 25 portfolios smaller than for the FF model. In particular for portfolios 1 (smallest capitalization, lowest $\mathrm{BE} / \mathrm{ME}$ ) and 25 (biggest capitalization, highest BE/ME), which are notoriously problematic for most asset pricing models, the variances are 53.12 for $\mathrm{FF}$ versus 22.69 for $\mathrm{RS}$ and 10.19 for $\mathrm{FF}$ versus 7.25 for RS respectively. The good performance in pricing portfolio 25 (the $\widehat{\alpha}$ is clearly not significantly different from zero in regime 2) is a remarkable feature of our model. The conditional RS model therefore seems to fit the data very well, sensibly better than the unconditional FF model.

Regarding the pricing errors $\widehat{\alpha}$, the FF model produces an average mispricing of 0.24 . For the RS model, once we weight each $\widehat{\alpha}$ with the ex-post regime probabilities, we get an average mispricing of 0.25 , i.e. 25 basis point monthly. Looking at the $t$-values in Table 10, we observe that only five $\widehat{\alpha}$ s are not significantly different from zero in the FF model. Similarly, only three portfolios' $\widehat{\alpha} \mathrm{s}$ are insignificant in regime 1 of the $\mathrm{RS}$ model, albeit as much as eleven $\widehat{\alpha} \mathrm{s}$ are not significant different from zero in regime two. The pricing performance of the two models is thus comparable. However, the RS model appears to have a much better pricing performance in regime 2 .

Figures 4 to 6 and Table 3 report the values of the $\widehat{\beta}_{\mathrm{s}}$ for the FF and the RS model. The $\widehat{\beta}_{\mathrm{S}}$ for both the FF and the RS model are of comparable magnitude, i.e. about one, with the exception of small stocks, whose $\widehat{\beta}_{\mathrm{s}}$ are slightly higher (average $\widehat{\beta}$ of 1.74 ).

The pattern for $\widehat{\gamma}$ (the factor loading on SMB, see Figures 7 to 9 and Table 3 ) is somewhat similar. Our benchmark FF model, in accordance with the findings of Fama/French $(1993,1996) \hat{\gamma}>1$ for small stocks, $\widehat{\gamma} \approx 0.5$ for value (i.e. high BE/ME) and growth (i.e. low BE/ME) stocks and $\hat{\gamma}<0$ for big stocks. The negative factor loading for big stocks implies lower average returns, which 
is a well documented fact. On the other hand, regime 2 presents a significantly different picture. The $\widehat{\gamma}_{\mathrm{s}}$ are larger for all portfolios in our sample. The increase is largest for growth $(0.56 \rightarrow 0.79)$ and value stocks $(0.56 \rightarrow 0.86)$.

The factor loadings on the HML factor, $\widehat{\delta}$, (Figures 10 to 12 and Table 3 ) in our regime 1 are quite similar in magnitude and sign to those of the FF model and of the rest of the literature, namely negative for growth stocks and increasing in the BE/ME quintiles, approaching 1 for value stocks. Again, the picture is very different in regime 2 . The $\widehat{\delta}_{\mathrm{s}}$ are higher for all portfolios: 0.32 $\rightarrow 1.22$ for small stocks, $0.77 \rightarrow 1.45$ for value stocks, $0.23 \rightarrow 0.79$ for big stocks and, strikingly, $-0.26 \rightarrow 0.20$ for growth stocks.

To sum up the results from the time series analysis, we find that the pricing accuracy of the RS-model is at least as good as that of the FF model. For some portfolios it is clearly better. In regime 1 the factor loadings are similar to those estimated for the FF model, and so is for the $\widehat{\beta}_{\mathrm{s}}$ in regime 2 . On the other hand, regime two is a state characterised by higher covariation of all portfolios with both the HML and SMB portfolios. Regime 2 are times in which the market as a whole is not behaving very differently as in regime 1 , however the portfolios riskiness with respect to the risk factors proxied by HML and SMB is considerably higher. In a recent contribution, Franzoni (2002) observes that the beta of value and small stocks has decreased significantly over the past sixty years. In particular, the value stocks beta has dropped by about $77 \%$, from 2.2 in the early forties to below 0.50 in the late nineties. However, Franzoni (2002) is really testing only a conditional version of the CAPM, thus not including HML and SMB as additional sources of risk. Our results provide evidence that the declining beta may be the consequence of this omission. Regime 2 is in fact characterised by higher overall exposure to HML and SMB, and this regime, as shown below, was more likely in the seventies, eighties and in particular early nineties as in the forties. This may well partly account for the observation by Franzoni (2002), since HML and SMB correlate positively with the market. 


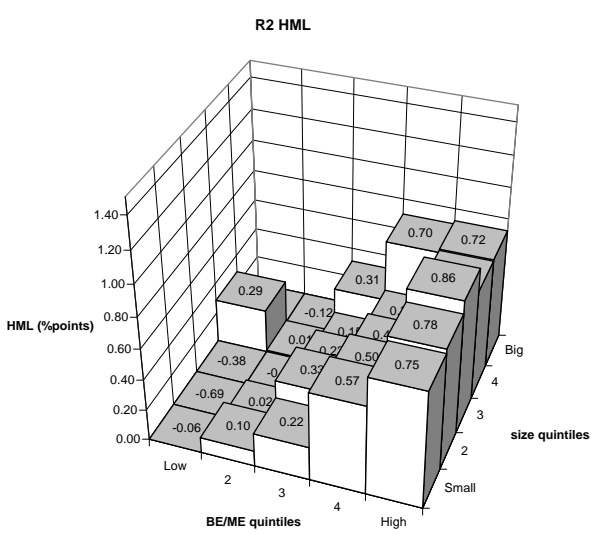

Fig. 1. FF alpha for all 25 portfolios

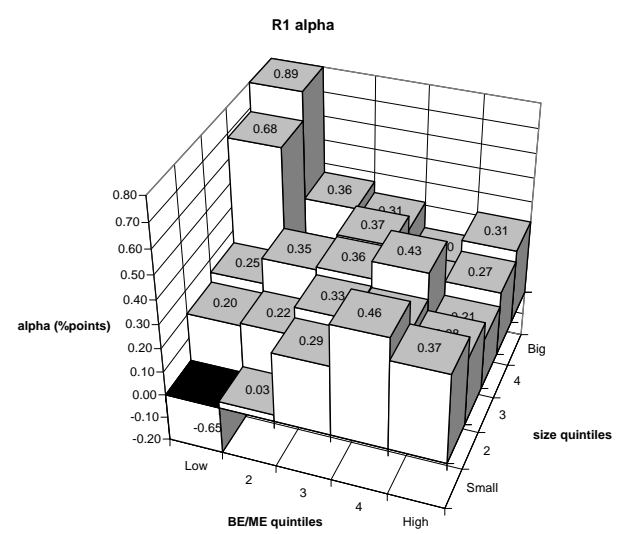

Fig. 2. Regime 1 alpha for all 25 portfolios

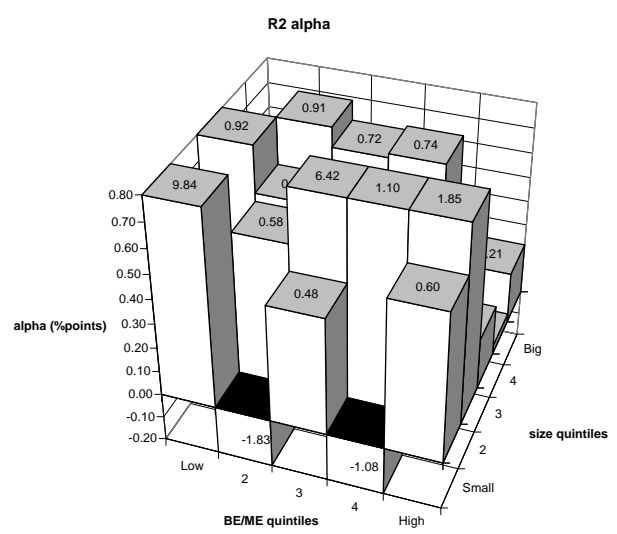

Fig. 3. Regime 2 alpha for all 25 portfolios 


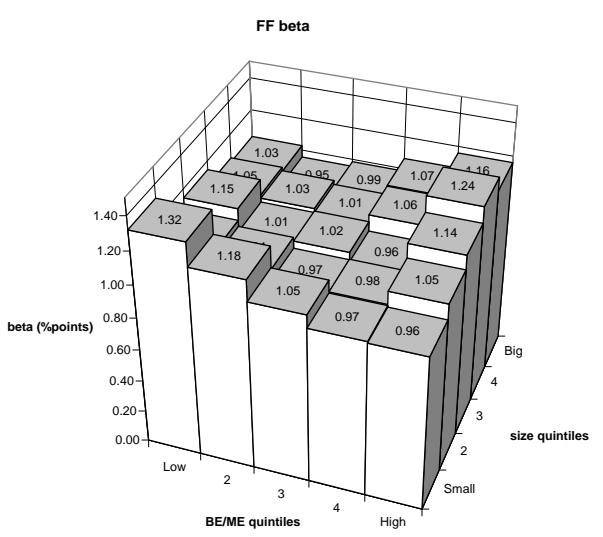

Fig. 4. FF beta for all 25 portfolios

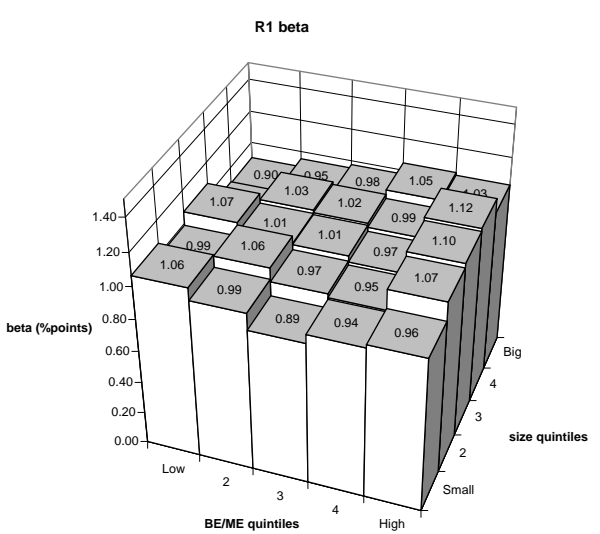

Fig. 5. Regime 1 beta for all 25 portfolios

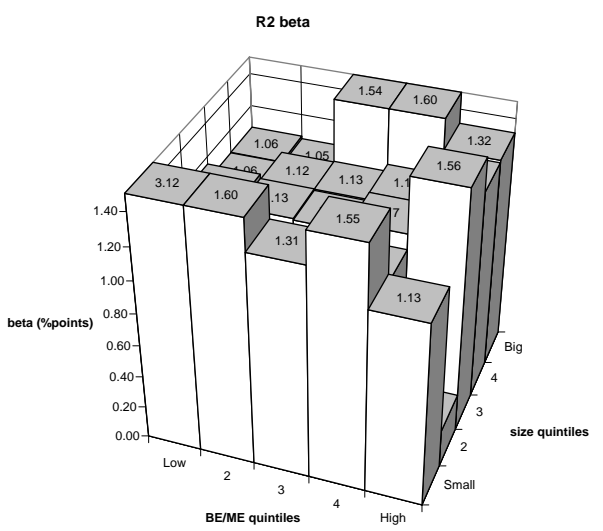

Fig. 6. Regime 2 beta for all 25 portfolios 


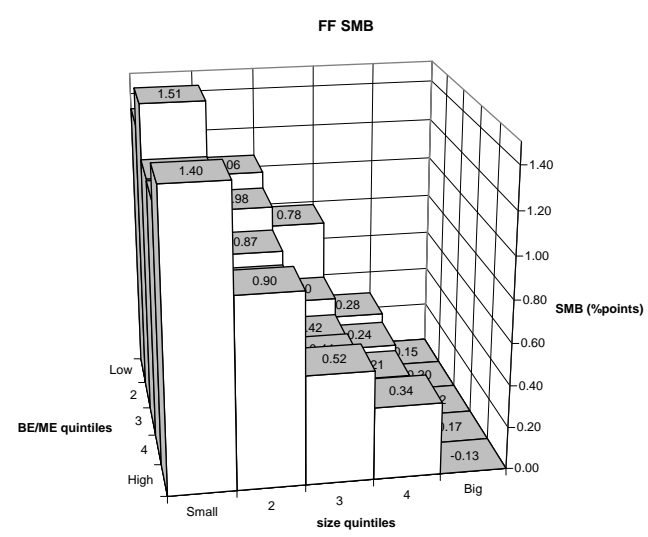

Fig. 7. FF smb for all 25 portfolios

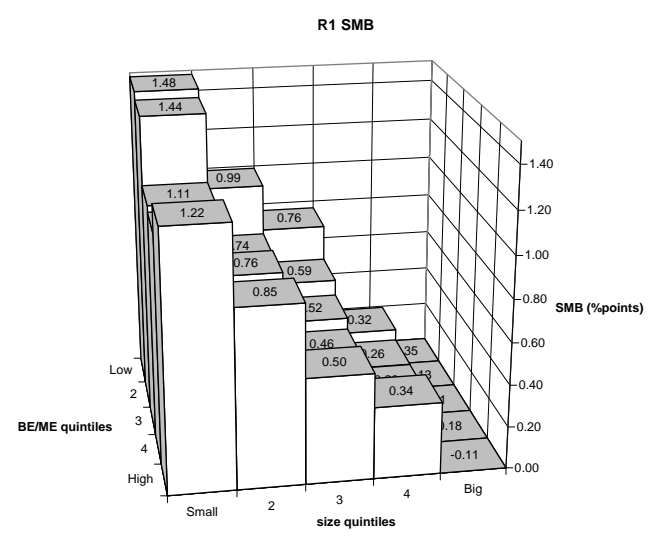

Fig. 8. Regime $1 \mathrm{smb}$ for all 25 portfolios

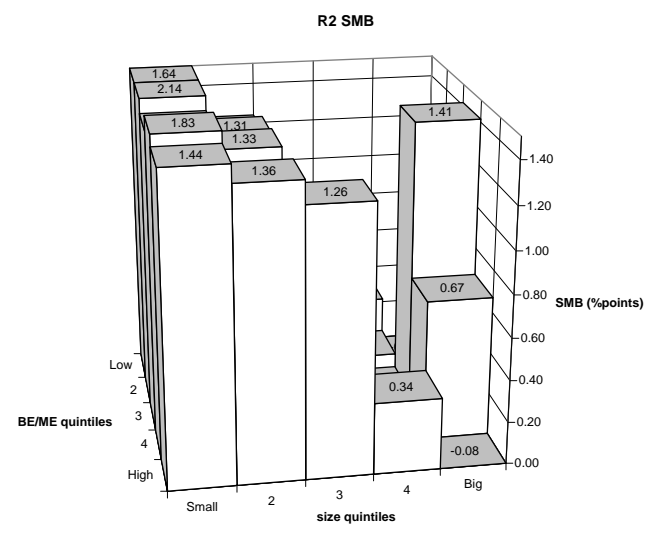

Fig. 9. Regime $2 \mathrm{smb}$ for all 25 portfolios 


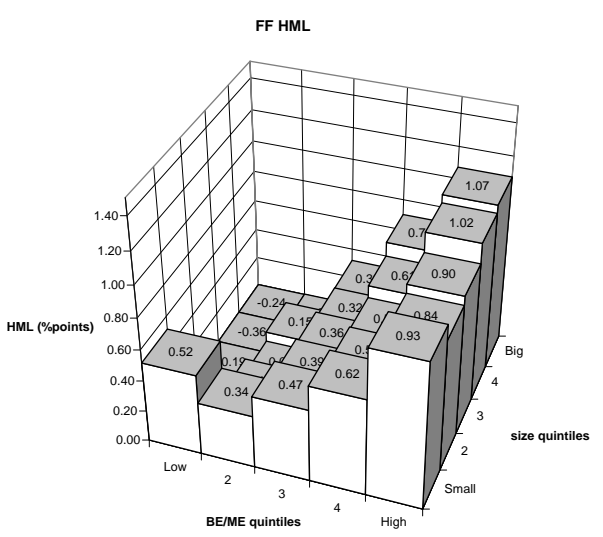

Fig. 10. FF hml for all 25 portfolios

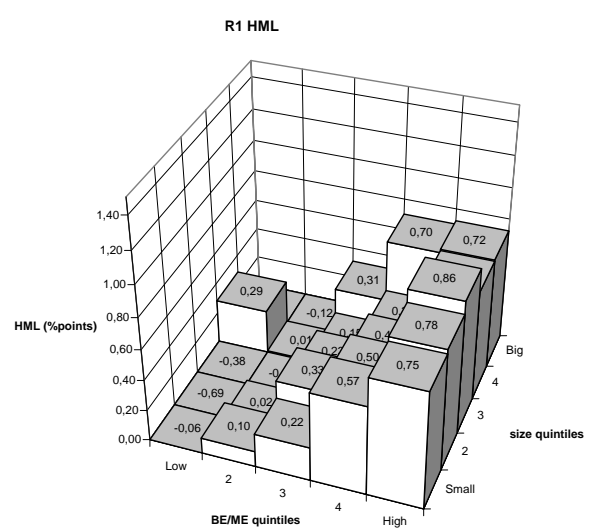

Fig. 11. Regime $1 \mathrm{hml}$ for all 25 portfolios

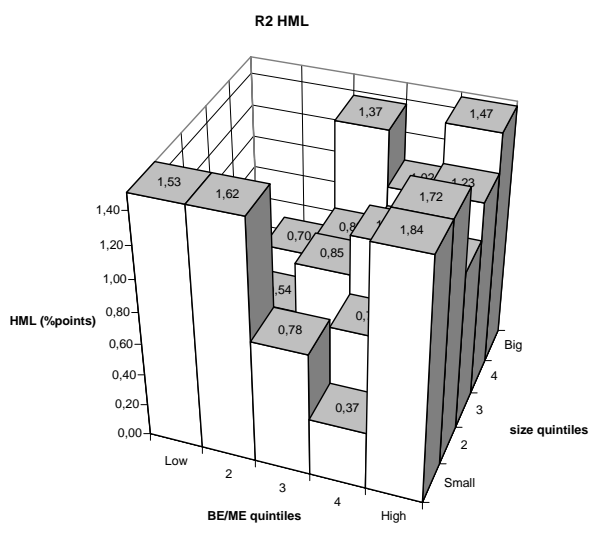

Fig. 12. Regime $2 \mathrm{hml}$ for all 25 portfolios 


\begin{tabular}{crrrrrrrrrrr}
\hline \multicolumn{1}{c}{ Fama French } & \multicolumn{1}{c}{ Regime switching } \\
& Low & 2 & 3 & 4 & High & Low & 2 & 3 & 4 & High \\
Small & -0.43 & -0.11 & 0.16 & 0.30 & 0.24 & Small & -0.50 & -0.13 & 0.19 & 0.23 & 0.26 \\
2 & -0.15 & 0.05 & 0.15 & 0.10 & -0.06 & 2 & -0.18 & 0.07 & 0.14 & 0.18 & 0.06 \\
3 & 0.08 & 0.06 & 0.01 & 0.01 & -0.11 & 3 & 0.01 & 0.08 & 0.08 & 0.15 & -0.13 \\
4 & 0.10 & -0.06 & 0.00 & -0.01 & -0.17 & 4 & 0.06 & -0.02 & 0.12 & 0.03 & -0.14 \\
Big & 0.23 & -0.05 & 0.05 & -0.12 & -0.09 & Big & 0.09 & 0.01 & -0.07 & -0.16 & -0.14 \\
\hline
\end{tabular}

Table 6

Pricing errors for all 25 portfolios based on Fama-MacBeth cross-sectional regressions.

\subsection{Fama/MacBeth cross sectional regressions}

We further implement the Fama and MacBeth (1973) cross sectional test. Again, the results for the RS model are quite encouraging. The average $R^{2}$ over 858 cross sectional regressions, for July 1931 to December 2002, is $37.99 \%$ for the RS model and $37.31 \%$ for the FF model. The average cross sectional pricing error is 0.012 for the RS model and 0.006 for FF. The hypothesis of zero mean alphas cannot be rejected for any of the models. We then test the validity of the two RS regressions individually. The average pricing error is 0.009 for regime 1 and 0.011 for regime 2. Again, the hypothesis or zero mean alphas cannot be rejected for any of the two regressions. Validity of both state-dependent regressions is of course necessary for the RS model to be valid as a whole. Details on the pricing errors for single portfolios can be found in Table 6, interestingly the RS model does a particularly good job at pricing growth stocks, which are well known to present a particular challenge to asset pricing models (e.g. Campbell and Vuoltenenaho (2002)). Again, and in contrast to most of the early conditional multifactor models, the RS model is not rejected. It provides a description of assets average excess returns which is at least as good as the unconditional FF model and its pricing performance is significantly better in state 2 .

\subsection{Economic interpretation of Regime probabilities}

In the philosophy of Merton's ICAPM, we now ask whether the alternance and the characteristics of the two regimes are in some way linked to any underlying economic state variable. This interpretation also permits to contribute in an original way to the riks/non-risk debate, e.g. if we can show that a particular state occurs when key economic series or economic events suggest a higher compensation for risk by the market participants, then our model favors the risk-based explanation. 
Simple visual inspection of the plot of aggregate regime probabilities (Figure 13) yields very interesting insights. In particular, our interpretation of regime 1 as a normal and regime 2 as a distressed regime is again supported. A sharp drop in the probability ofl regime 1 is an indicator that the regime 2 could follow. As regimes are unobservable, we can only infer on the regime by looking at these transition probabilities. Figure 13 depicts the average probability of regime 1 over all 25 portfolios, plotted together with the endof-month default spread. Interestingly, the regime 1 probability sharply falls precisely at historically known times of financial distress, i.e. changes of the investors perceptions of risk on the market.

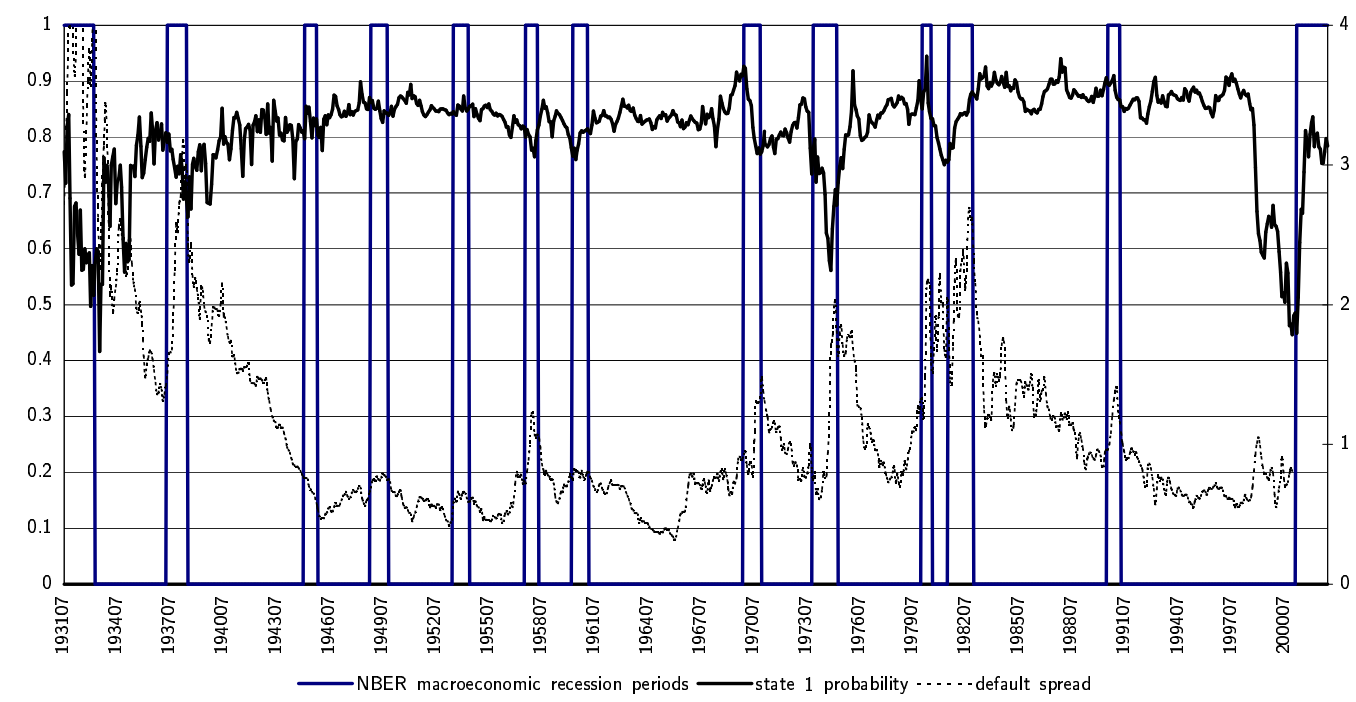

Fig. 13. NBER macroeconomic recession periods, estimated probability being in regime 1 , averaged over all 25 portfolios, and default spread. The default spread is the end-of-month difference between annualized yields an Aaa and Baa corporate bonds. The probability is measured on the right vertical axis and the default spread on the left vertical axis.

Finally, it is interesting to notice the difference in regime probabilities for small and large caps and for growth and value stocks. Figure 14 presents the probability of being in regime 1 for small and large caps together with the default spread. By financial distress, we mean here times of high aggregate, nondiversifiable, liquidity and credit risk, rather than overall equity market contractions. Regime 1 probability displays in fact a strong correlation with the US default spread but quite little correlation with the main equity market indices. Consider for example fall 1987: regime 1 probability is very high despite the market crash. On other hand, in 1991 and 1997 the equity market was trending upwards, but regime 1 probabilities suddenly collapsed, a few month ahead of sharp increases in the credit spread due to well known financial episodes. Regime 2 seems therefore to characterise times when investors are particularly concerned with financial, and in particular credit distress, even though the market as a whole does not fall. 


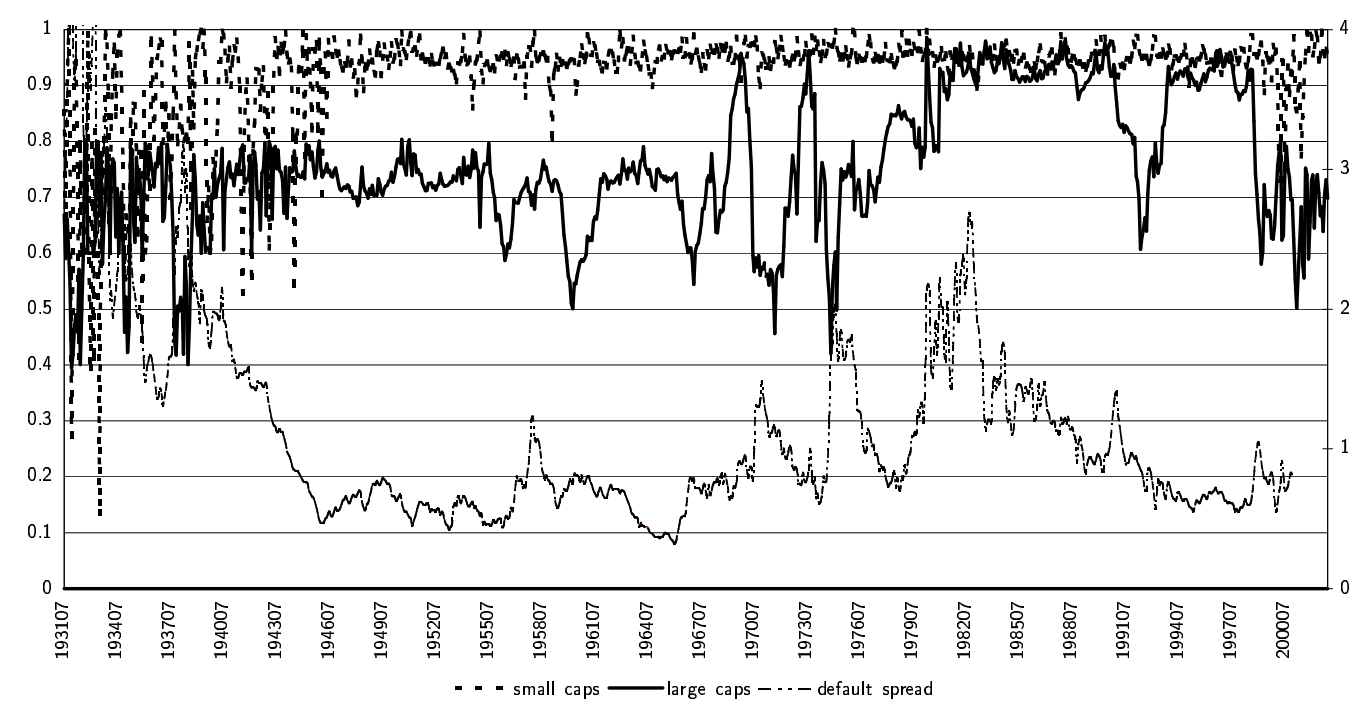

Fig. 14. Estimated probability being in regime 1 for small and large caps and default spread. The default spread is the end-of-month difference between annualized yields an Aaa and Baa corporate bonds. The probability is measured on the right vertical axis and the default spread on the left vertical axis.

Market perception of distress risk seems to be much more volatile for large than for small caps. Small caps were perceived as more likely to be in a distress regime than large caps during the 30s and 40s. From the mid 40s onwards, large caps always had a larger probability of regime 2 , with small caps only reaching below the $80 \%$-probability of regime 1 in one occasion in half a century, namely in 2000. While small caps were generally more risky than large caps in both regimes (explaining their higher historical average returns), risk perception for large caps increased very sharply during the oil crises, the 1987 crash, the Asian crisis and the IT bubble. Figure 15 presents the results for growth versus value portfolios. Growth stocks constantly had, over the last 70 years, a higher regime 2-probability. Since the seventies, however, this probability seems to have stabilized to a lower level, with the exception of a new historical high of $60 \%$ at the beginning of 2000 . We discuss the possibility to exploit regime switches through dynamic style-rotation investment strategies in a forthcoming paper.

\section{Conclusions}

We have presented a simple state-dependent version of the Fama and French three-factor model. Testing for its validity using both a time series and a cross sectional approach, we find that the model improves pricing performance over the unconditional Fama and French model. The magnitude of the estimated factor loadings on the HML and the SMB factors differ dramatically 


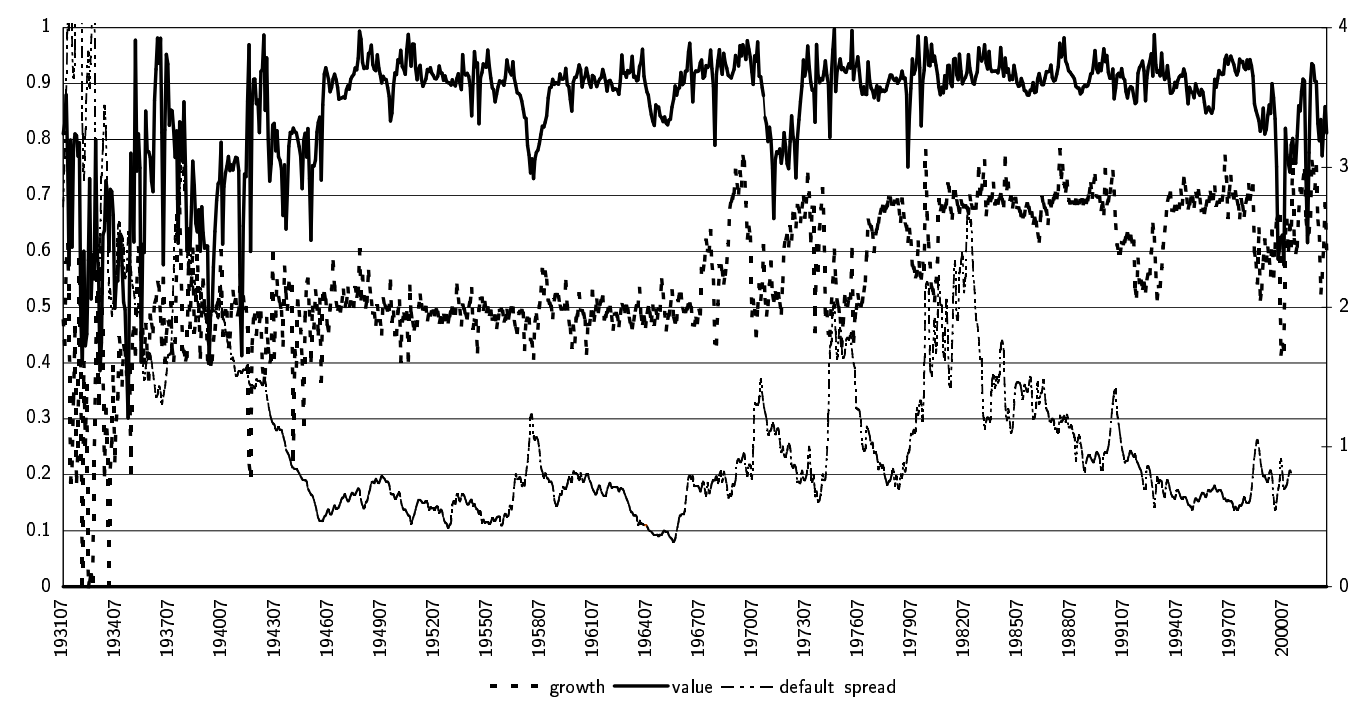

Fig. 15. Estimated probability being in regime 1 for value and growth stocks and default spread. The default spread is the end-of-month difference between annualized yields an Aaa and Baa corporate bonds. The probability is measured on the right vertical axis and the default spread on the left vertical axis.

across regimes, thus leading the unconditional model to massive overpricing of some portfolios (in particular value stocks) and underpricing of others (growth stocks), relative to the state-dependent model. On the other hand, the factor loading on the excess return of the market portfolio, is quite homogeneous across states and portfolios in both the conditional and unconditional model.

Fama and French (1993) interpret the average HML return as a risk premia related to relative financial distress. They refer to Fama and French (1995), providing evidence that low $\mathrm{BE} / \mathrm{ME}$ is typical of firms that have persistently high earnings, while high $\mathrm{BE} / \mathrm{ME}$ is associated with persistently low earnings and is now near financial distress. However, associating a common factor in returns to an economic state variable does not yet necessarily imply that the state variable is of special hedging concern to investors, hence producing a risk premia. The question why relative distress should be of special concern to investor still remains unexplained. A possible explanation is that in times of credit or liquidity distress, a typical value stock, which has a price that has been driven down by repeated financial difficulties and is near financial distress, will perform very badly. This is precisely what investors least want in hard times.

Our estimation results provide some support to this interpretation. In the last part of this paper, we endogenously estimate the transition probabilities of both regimes and find the average probability of regime 2 to have a particularly high predictive power with respect to the major times of aggregate financial distress over the last 70 years. This probability is quite strongly correlated 
with the default spread over the time period considered. The link between HML, SMB and macroeconomic variables is currently a very active subject of research. Further results and some international evidence will be presented shortly in a companion paper.

\section{References}

Banz, R. W., 1981. The relationship between return and market value of common stocks. Journal of Financial Economics 9, 3-18.

Black, F., Jensen, M., Scholes, M., 1972. The capital asset pricing model: Some empirical tests. In: Jensen, M. C. (Ed.), Studies in the Theory of Capital Markets. Praeger, New York, pp. 79-121.

Campbell, J. Y., Vuoltenenaho, T., 2002. Bad beta, good beta, mimeo.

Connor, G., Korajczyk, R. A., 1986. Performance measurement with the arbitrage pricing theory: A new framework for analysis. Journal of Financial Economics 17, 255-289.

Daniel, K., Titman, S., 1997. Evidence on the characteristics of cross sectional variation in stock returns. Journal of Finance 52, 1-33.

Fama, E. F., French, K. R., 1993. Common risk factors in the returns on stock and bonds. Journal of Financial Economics 33, 3-56.

Fama, E. F., French, K. R., 1995. Size and book-to-market factors in earnings and returns. Journal of Finance 50, 131-155.

Fama, E. F., French, K. R., 1996. Multifactor explanations of asset pricing anomalies. Journal of Finance 51, 55-84.

Fama, E. F., French, K. R., 1998. Value versus growth: the international evidence. Journal of Finance 53, 1975-1999.

Fama, E. F., MacBeth, J., May-June 1973. Risk, return and equilibrium: Empirical tests. Journal of Political Economy 81, 607-636.

Ferson, W. E., Harvey, C. R., 1999. Conditioning variables and the cross section of stock returns. Journal of Finance 54 (4), 1325 - 1360.

Franzoni, F., 2002. Where is the beta going? the riskness of value and small stocks, mimeo.

Ghysels, E., 1998. On stable factor structures in the pricing of risk: Do tyme varying betas help or hurt. Journal of Finance 53, 549-574.

Hamilton, J. D., 1990. Analysis of time series subject to changes in regime. Journal of Econometrics 45, 39-70.

He, J., Kan, R., Ng, L., Zhang, C., 1996. Tests of the relations among marketwide factors, firm-specific variables and stock returns using a conditional asset pricing model. Journal of Finance 69, 1891-1908.

Lakonishok, J., Schleifer, A., Vishny, R. W., 1994. Contrarian investment, extrapolation and risk. Journal of Finance 49, 1541-1578.

MacKinlay, A. C., 1995. Multifactor models do not explain deviations from the CAPM. Journal of Financial Economics 38, 3-28. 
Rosenberg, B., Kenneth, R., Lanstein, R., 1985. Persuasive evidence of market inefficiency. Journal of Portfolio Management 11, 9-17.

van Norden, S., Vigfusson, R., 1996. Regime-switching models. Working Paper 96-3, Bank of Canada.

Wang, K. Q., 2002. Asset pricing with conditioning information: a new test. Ph.D. thesis, University of Chicago. 